\title{
Assessment of calculation methods for calcium carbonate saturation in drinking water for DIN 38404-10 compliance
}

\author{
P. J. de Moel ${ }^{1,2}$, A. W. C. van der Helm ${ }^{2,3}$, M. van Rijn ${ }^{4}$, J. C. van Dijk ${ }^{2,5}$, and W. G. J. van der Meer ${ }^{2,6}$ \\ ${ }^{1}$ Omnisys, Eiberlaan 23, 3871 TG, Hoevelaken, the Netherlands \\ ${ }^{2}$ Delft University of Technology, Faculty of Civil Engineering and Geosciences, Department of Water \\ Management, P.O. Box 5048, 2600 GA, Delft, the Netherlands \\ ${ }^{3}$ Waternet, P.O. Box 94370,1090 GJ, Amsterdam, the Netherlands \\ ${ }^{4}$ Vitens, P.O. Box 1205, 8001 BE Zwolle, the Netherlands \\ ${ }^{5}$ VanDijkConsulting, Rossenberglaan 9, 3833 BN, Leusden, the Netherlands \\ ${ }^{6}$ Oasen, P.O. Box 122, 2800 AC, Gouda, the Netherlands \\ Correspondence to: P. J. de Moel (p.j.demoel@tudelft.nl)
}

Received: 11 July 2013 - Published in Drink. Water Eng. Sci. Discuss.: 1 August 2013

Revised: 25 October 2013 - Accepted: 29 October 2013 - Published: 18 November 2013

\begin{abstract}
The new German standard on the calculation of calcite saturation in drinking water, DIN 3840410, 2012 (DIN), marks a change in drinking water standardization from using simplified equations applicable for nomographs and simple calculators to using extensive chemical modeling requiring computer programs. The standard outlines the chemical modeling and presents a dataset with 10 water samples for validating used computer programs. The DIN standard, as well as the Standard Methods 2330 (SM) and NEN 6533 (NEN) for calculation of calcium carbonate saturation in drinking water were translated into chemical databases for use in PHREEQC (USGS, 2013). This novel approach gave the possibility to compare the calculations as defined in the standards with calculations using widely used chemical databases provided with PHREEQC. From this research it is concluded that the computer program PHREEQC with the developed chemical database din38404-10_2012.dat complies with the DIN standard for calculating Saturation Index (SI) and Calcite Dissolution Capacity (Calcitlösekapazität) or Calcium Carbonate Precipitation Potential (CCPP). This compliance is achieved by assuming equal values for molarity as used in DIN (obsolete) and molality as used in PHREEQC. From comparison with widely used chemical databases it is concluded that the use of molarity limits the use of DIN to a maximum temperature of $45^{\circ} \mathrm{C}$. For current practical applications in water treatment and drinking water applications, the PHREEQC database stimela.dat was developed within the Stimela platform of Delft University of Technology. This database is an extension of the chemical database phreeqc.dat and thus in compliance with SM. The database stimela.dat is also applicable for hot and boiling water, which is important in drinking water supply with regard to scaling of calcium carbonate in in-house drinking water practices. SM and NEN proved to be not accurate enough to comply with DIN, because of their simplifications. The differences in calculation results for DIN, SM and NEN illustrate the need for international unification of the standard for calcium carbonate saturation in drinking water.
\end{abstract}

\section{Introduction}

In general, calculation of calcium carbonate saturation in drinking water is performed with a simplification of the processes as shown in Table 1, in which ion pairs are neglected and calcite is assumed to be the determining crys- talline phase. The equations for equilibrium constants in Table 1 do not apply to the concentrations of diluted species, but to their (relative) activities which are smaller than the concentrations because of their interaction with each other and with the surrounding water molecules (dipoles). 
Table 1. Processes generally used for description of calcium carbonate $\left(\mathrm{CaCO}_{3}\right)$ saturation in drinking water.

\begin{tabular}{lll}
\hline Part & Reaction equations & Equilibrium constants \\
\hline Dissolution/precipitation of $\mathrm{CaCO}_{3}$ & $\mathrm{CaCO}_{3}(\mathrm{~s}) \leftrightarrow \mathrm{Ca}^{2+}+\mathrm{CO}_{3}^{2-}$ & $\mathrm{K}_{\mathrm{s}}=\left\{\mathrm{Ca}^{2+}\right\} \cdot\left\{\mathrm{CO}_{3}^{2-}\right\}$ \\
\hline Dissociation of carbon dioxide & $\mathrm{CO}_{2}+\mathrm{H}_{2} \mathrm{O} \leftrightarrow \mathrm{HCO}_{3}^{-}+\mathrm{H}^{+}$ & $\mathrm{K}_{1}=\left\{\mathrm{HCO}_{3}^{-}\right\} \cdot\left\{\mathrm{H}^{+}\right\} /\left\{\mathrm{CO}_{2}\right\}$ \\
$\mathrm{CO}_{2}+\mathrm{H}_{2} \mathrm{O}=\mathrm{H}_{2} \mathrm{CO}_{3}$ & $\mathrm{HCO}_{3}^{-} \leftrightarrow \mathrm{CO}_{3}^{2-}+\mathrm{H}^{+}$ & $\mathrm{K}_{2}=\left\{\mathrm{CO}_{3}^{2-}\right\} \cdot\left\{\mathrm{H}^{+}\right\} /\left\{\mathrm{HCO}_{3}^{-}\right\}$ \\
\hline Ionisation of water & $\mathrm{H}_{2} \mathrm{O}(\mathrm{l}) \leftrightarrow \mathrm{OH}^{-}+\mathrm{H}^{+}$ & $\mathrm{K}_{\mathrm{w}}=\left\{\mathrm{H}^{+}\right\} \cdot\left\{\mathrm{OH}^{-}\right\}$ \\
& & $\lg \left\{\mathrm{H}^{+}\right\}=-\mathrm{pH}$ \\
\hline
\end{tabular}

$\{\mathrm{X}\}=$ relative activity of dissolved species/ion $\mathrm{X}$.

The Saturation Index (SI) is a measure of the thermodynamic driving force to the equilibrium state. The definition of SI for precipitation/dissolution reactions with the equilibrium constants of Table 1 gives:

$$
\begin{aligned}
\mathrm{SI} & =\lg \left(\frac{\left\{\mathrm{Ca}^{2+}\right\}\left\{\mathrm{CO}_{3}^{2-}\right\}}{\mathrm{K}_{\mathrm{S}}}\right) \\
& =\lg \left\{\mathrm{Ca}^{2+}\right\}+\lg \left\{\mathrm{HCO}_{3}^{-}\right\}+\lg \mathrm{K}_{2}-\lg \mathrm{K}_{\mathrm{S}}+\mathrm{pH}
\end{aligned}
$$

Langelier combined the first four terms in the last part of Eq. (1) into the parameter $-\mathrm{pH}_{\mathrm{s}}$ (Langelier, 1936). Therefore SI for calcium carbonate is often called Langelier Index (LI) or Langelier Saturation Index (LSI). The parameter SI is dimensionless, because the activities in Eq. (1) are relative dimensionless values compared to standard conditions (standard molality, $1 \mathrm{~mol} \mathrm{kgw}^{-1}$ ). This is also the case for $\mathrm{pH}$ and the $K$ values in Table 1 (Buck et al., 2002; Gamsjäger et al., 2008).

A practical parameter that is associated with the calcium carbonate saturation is the Calcium Carbonate Precipitation Potential (CCPP) (Standard Methods 2330, 2010), which is a generally used measure for the amount of calcium carbonate which theoretically can precipitate.

SI and CCPP are positive for oversaturated water, zero for saturated water, and negative for undersaturated water. Negative CCPP values are also reported as Calcium Carbonate Dissolution Potential, Calcite Dissolution Capacity or Aggressive Carbon dioxide. Calcium carbonate equilibrium or saturation according to Eq. (1) is shown in Fig. 1, assuming $\left\{\mathrm{HCO}_{3}^{-}\right\}=2\left\{\mathrm{Ca}^{2+}\right\}$. The $\mathrm{pH}$ at equilibrium is higher for water with lower calcium content, i.e. for softer water.

In December 2012, a new German standard for the calculation of calcium carbonate saturation in drinking water was released (DIN 38404-10, 2012, hereafter referred to as DIN). According to the DIN, it is no longer allowed to calculate the SI and CCPP with the simplifications described above. The DIN requires these parameters to be calculated with all specified aqueous species, including complexes with sulphate and phosphate. In order to do so, the DIN standard describes the calculation method with the chemical principles and a data set containing 10 water samples for validation of the calculation method or computer program used.

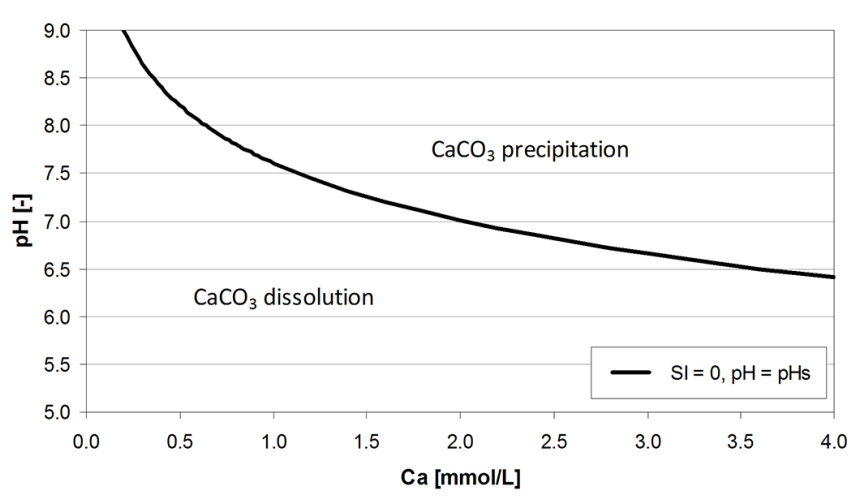

Figure 1. Calcium carbonate equilibrium or saturation $(\mathrm{SI}=0$, at $25^{\circ} \mathrm{C}$ and $\left.\left\{\mathrm{HCO}_{3}^{-}\right\}=2\left\{\mathrm{Ca}^{2+}\right\}\right)$ with over- and under-saturation i.e. calcium carbonate precipitation and dissolution.

The objective of this research is to determine the best calculation method for SI and CCPP in drinking water by testing the calculation methods described in the recent German standard (DIN 38404-10, 2012), the equivalent US standard (Standard Methods 2330, 2010, hereafter referred to as SM), the Dutch standard (NEN 6533, 1990, hereafter referred to as NEN) and a number of widely used databases for calculating chemical equilibria in water, with a validation set given in the DIN standard.

\section{Materials and methods}

\subsection{Calculation method DIN 38404-10}

Table 2 gives an overview of all elements, phases and dissolved species in DIN. For both calcium and magnesium this standard distinguishes eight different dissolved species. The standard covers only calcite as the least soluble crystalline form of $\mathrm{CaCO}_{3}$, and applies only to "water for distribution as drinking water". The standard requires that the concentrations of all the elements mentioned are known, as well as $\mathrm{pH}$ and temperature. Because of its complexity DIN requires an extensive iterative computer calculation for both SI and CCPP determination, the latter reported in DIN as Calcitlösekapazität (Calcite Dissolution Capacity). 
Table 2. Chemical elements, phases and dissolved species in DIN 38404-10 (2012).

\begin{tabular}{lll}
\hline Element & Phase & Dissolved species \\
\hline $\mathrm{Ca}$ & $\mathrm{CaCO}_{3}(\mathrm{~s})$ & $\mathrm{Ca}^{2+}, \mathrm{CaCO}_{3}^{0}, \mathrm{CaHCO}_{3}^{+}, \mathrm{CaOH}^{+}, \mathrm{CaSO}_{4}^{0}, \mathrm{CaH}_{2} \mathrm{PO}_{4}^{+}, \mathrm{CaHPO}_{4}^{0}, \mathrm{CaPO}_{4}^{-}$ \\
$\mathrm{Mg}$ & & $\mathrm{Mg}^{2+}, \mathrm{MgCO}_{3}^{0}, \mathrm{MgHCO}_{3}^{+}, \mathrm{MgOH}^{+}, \mathrm{MgSO}_{4}^{0}, \mathrm{MgH}_{2} \mathrm{PO}_{4}^{+}, \mathrm{MgHPO}_{4}^{0}, \mathrm{MgPO}_{4}^{-}$ \\
$\mathrm{Na}$ & & $\mathrm{Na}^{+}$ \\
$\mathrm{K}$ & & $\mathrm{K}^{+}$ \\
\hline $\mathrm{C}^{*}$ & $\mathrm{CaCO}_{3}(\mathrm{~s})$ & $\mathrm{H}_{2} \mathrm{CO}_{3}\left(=\mathrm{CO}_{2} \cdot \mathrm{aq}\right), \mathrm{HCO}_{3}^{-}, \mathrm{CO}_{3}^{2-}$ \\
$\mathrm{Cl}$ & & $\mathrm{Cl}^{-}$ \\
$\mathrm{N}$ & & $\mathrm{NO}_{3}^{-}$ \\
$\mathrm{S}^{*}$ & & $\mathrm{HSO}_{4}^{-}, \mathrm{SO}_{4}^{2-}$ \\
$\mathrm{P}^{*}$ & & $\mathrm{H}_{3} \mathrm{PO}_{4}, \mathrm{H}_{2} \mathrm{PO}_{4}^{-}, \mathrm{HPO}_{4}^{2-}, \mathrm{PO}_{4}^{3-}$ \\
$\mathrm{H}$ & $\mathrm{H}_{2} \mathrm{O}(\mathrm{l})$ & $\mathrm{H}^{+}, \mathrm{OH}^{-}$ \\
\hline
\end{tabular}

* The dissolved species already specified for the cations $\mathrm{Ca}$ and $\mathrm{Mg}$ are not repeated for the anions.

Chemistry in DIN is based on molarity ( $\mathrm{mol} \mathrm{L}^{-1}$ solution) instead of molality ( $\mathrm{mol} \mathrm{kg}^{-1}$ solvent i.e. water) as used in chemical thermodynamics (Gamsjäger et al., 2008). The values expressed as molarity and molality are equal for a solution with a density of $1 \mathrm{~kg} \mathrm{~L}^{-1}$ while assuming that the mass of the solution equals the mass of water.

\subsection{Calculation method Standard Methods 2330}

SM gives a set of equations for calculating the value for SI. For CCPP no analytical equation is available and the value can only be obtained by iterative computer calculations. SM distinguishes three crystalline forms of $\mathrm{CaCO}_{3}$ (calcite, vaterite and aragonite) and further only two aqueous species $\left(\mathrm{Ca}^{2+}\right.$ and $\left.\mathrm{HCO}_{3}^{-}\right)$, with the assumption that either all other species can be neglected or the reduction to these two aqueous species can be estimated. The influence of other ions is accounted for through the ionic strength and successively in the activity coefficients of $\mathrm{Ca}^{2+}$ and $\mathrm{HCO}_{3}^{-}$. The standards DIN, SM and NEN have slightly different defined parameters for alkalinity. Therefore, Total Inorganic Carbon $\left(\mathrm{C}_{\mathrm{T}}\right.$, or TIC) or Dissolved Inorganic Carbon (DIC) is used, which requires calculation of the concentrations of $\mathrm{CO}_{2}$ and $\mathrm{CO}_{3}^{2-}$ (via $\mathrm{K}_{1}$ and $\mathrm{K}_{2}$ ). Standard Methods gives $\mathrm{K}_{2}$ as published by Plummer and Busenberg (1982). This study uses $\mathrm{K}_{1}$ from the same publication. In Table 3 the chemical elements used in SM are shown.

\subsection{Calculation method NEN 6533}

Just as SM, NEN gives a set of equations for calculating the value for SI. For CCPP no analytical equation is available and the value can only be obtained by iterative computer calculations. NEN considers only $\mathrm{Ca}^{2+}, \mathrm{HCO}_{3}^{-}$and $\mathrm{H}^{+}$and uses only one crystalline form of $\mathrm{CaCO}_{3}$ (calcite), but adjusts the solubility product of $\mathrm{CaCO}_{3}$, in order to take into account the soluble species of $\mathrm{CaCO}_{3}^{0}$ and $\mathrm{CaHCO}_{3}^{+}$, by decreasing the $\mathrm{pK}_{\mathrm{S}}$ value with 0.037 (at $0{ }^{\circ} \mathrm{C}$ ) ranging to 0.057 (at $30^{\circ} \mathrm{C}$ ) based on a combination of $\mathrm{K}_{\mathrm{s}}$ values from Plummer and Busenberg
Table 3. Chemical elements, phases and dissolved species in Standard Methods 2330 (2010).

\begin{tabular}{|c|c|c|}
\hline Element & Phase & Dissolved species \\
\hline $\mathrm{Ca}$ & $\mathrm{CaCO}_{3}(\mathrm{~s})^{\mathrm{a}}$ & $\mathrm{Ca}^{2+\mathrm{b}}$ \\
\hline $\mathrm{C}$ & $\mathrm{CaCO}_{3}(\mathrm{~s})^{\mathrm{a}}$ & $\mathrm{HCO}_{3}^{-}, \mathrm{CO}_{3}^{2-\mathrm{c}}$ \\
\hline $\mathrm{H}$ & $\mathrm{H}_{2} \mathrm{O}(\mathrm{l})$ & $\mathrm{H}^{+}, \mathrm{OH}^{-\mathrm{c}}$ \\
\hline \multicolumn{3}{|c|}{$\begin{array}{l}\text { a three crystalline forms of } \mathrm{CaCO}_{3} \text { : calcite, aragonite and } \\
\text { vaterite } \\
\mathrm{b} \text { ion pairs } \mathrm{CaHCO}_{3}^{+}, \mathrm{CaSO}_{4}^{0} \text { and } \mathrm{CaOH}^{+} \text {by assumption } \\
\text { only, for estimation of }\left[\mathrm{Ca}^{2+}\right] \\
{ }^{c} \mathrm{CO}_{3}^{2-}, \mathrm{OH}^{-} \text {, and } \mathrm{H}^{+} \text {only in Alkalinity, for estimation of } \\
{\left[\mathrm{HCO}_{3}^{-}\right]}\end{array}$} \\
\hline
\end{tabular}

(1982) and Jacobson and Langmuir (1974). Recent literature assesses the approach for $\mathrm{K}_{\mathrm{s}}$ used by Jacobson and Langmuir (1974) as incorrect (de Visscher et al., 2012). NEN uses the term aggressiveness for calcium carbonate expressed as aggressive carbon dioxide.

\subsection{Calculation software PHREEQC}

The computer program PHREEQC, developed by the United States Geological Survey (USGS, 2013) is the de facto international standard for calculating chemical equilibria in groundwater. This program (PHREEQC.exe) solves the mathematical equations that are generated from a chemical database (.dat) and an input file (.pqi), both adjustable by the user (Parkhurst and Appelo, 2013). PHREEQC version 3.0.3 was used to assess the different calculation methods for SI and CCPP according to DIN, SM, NEN and the chemical databases from Table 4. All databases in the upper part of Table 4 are distributed with PHREEQC version 3.0.3 in which "phreeqc.dat" is the default database. 
Table 4. Databases in the PHREEQC data format for calculating chemical equilibria in water.

\begin{tabular}{lll}
\hline Database & Institution & Program \\
\hline phreeqc.dat & US-USGS & PHREEQC \\
wateq4f.dat & US-USGS & WATEQ4F \\
minteq.v4.dat & US-EPA & MINTEQA2, VISUAL MINTEQ and MINEQL+ \\
llnl.dat & US-LLNL & EQ3/6 and Geochemist's Workbench (GWB) \\
sit.dat & FR-ANDRA & PHREEQC \\
pitzer.dat & US-USGS & PHRQPITZ \\
\hline stimela.dat & NL-Omnisys/Delft UT & PHREEQC/Stimela \\
din38404-10_2012.dat & NL-Omnisys/Delft UT & PHREEQC/Stimela \\
sm2330_2010.dat & NL-Omnisys/Delft UT & PHREEQC/Stimela \\
nen6533_1990.dat & NL-Omnisys/Delft UT & PHREEQC/Stimela \\
\hline
\end{tabular}

\subsection{Calculation method with widely used chemical databases}

Several widely used computer programs for calculating chemical equilibria in water have been developed by different institutions for different purposes. These programs include their own chemical database, all in their own specific data format. The most prominent databases are also available in the data format for the computer program PHREEQC. The upper part in Table 4 shows a number of databases available in the PHREEQC data format that are able to calculate SI and CCPP, with their institution of origin and the computer program for which they were originally developed.

The computer program PHREEQC and its related database phreeqc.dat is widely used and also is listed in Standard Methods for use of calculation of calcium carbonate saturation indices. The phreeqc.dat database was developed for the calculation of chemical equilibria in groundwater. The calcium carbonate chemistry in the database phreeqc.dat is based on Nordstrom et al. (1990), which is the most recent update of the much-cited publications of Jacobson and Langmuir (1974), Truesdell and Jones (1974) and Plummer and Busenberg (1982). Nordstrom et al. (1990) give equilibrium constants for natural water for a temperature range from 0 to $100^{\circ} \mathrm{C}$, at a pressure of $1 \mathrm{bar}$. Their dataset is also adopted by Stumm and Morgan (1996). In phreeqc.dat more ion pairs are included than in DIN, such as ion pairs of sodium with sulphate, phosphate, bicarbonate, carbonate and hydroxide.

The database wateq 4 f.dat is also based on Nordstrom et al. (1990) and therefore almost identical to phreeqc.dat for SI and CCPP calculation. The minteq.v4.dat database has been developed by US EPA, for version 4 of MINTEQA2. The llnl.dat database, compiled by the Lawrence Livermore National Laboratory (Daveler and Wolery, 1992), is by far the most extensive database with respect to thermodynamic equilibrium constants. The databases sit.dat and pitzer.dat are in accordance with the specific ion interaction theory (SIT) of Grenthe et al. (1997) respectively the specific ion interaction model of Pitzer (1973). They were designed to extend the calculation methods for natural water with a high con- tent of dissolved salts (ionic strength $>500 \mathrm{mmol} \mathrm{kgw}^{-1}$ ) and they were calibrated on, for instance, seawater and brine. In pitzer.dat, oxygen (dissolved and as gas phase) and all compounds with $\mathrm{N}$ and $\mathrm{P}$ are not included.

\subsection{Calculation method with specific chemical databases}

The specifically developed chemical databases are summarized in the lower part of Table 4. The stimela.dat database is developed specifically for water treatment by Omnisys and Delft University of Technology as part of the Stimela modeling environment (van der Helm and Rietveld, 2002). The database is based on phreeqc.dat with extra species and phases to comply to SM and DIN, and with additional redox-uncoupled elements (de Moel et al., 2013). The stimela.dat database will be used in further calculations instead of phreeqc.dat.

The chemical specifications of DIN were converted into a newly developed database for PHREEQC (referred to as “din38404-10_2012.dat”). Starting with phreeqc.dat as a basis, all elements, species and phases were removed which are not mentioned in DIN. An exception was made for the parts of the database that PHREEQC needs in order to run, such as the elements $\mathrm{H}$ and $\mathrm{O}$, the gases $\mathrm{O}_{2}$ and $\mathrm{CO}_{2}$, and $\mathrm{H}_{2} \mathrm{O}$, alkalinity and the oxidation state $(E)$. Subsequently the numerical values for the equilibrium constants of the reactions ( $\log _{-} \mathrm{k}$ in PHREEQC; $\lg \left(\mathrm{K}_{0}\right)$ in DIN), the change in enthalpy of the reactions (delta_h in PHREEQC; $\Delta \mathrm{H}$ in DIN) and the activity coefficients (gamma in PHREEQC; $f(i)$ in DIN with its ion size parameter $g(i)$ ) were adjusted to the values given in DIN. The last step for building din38404-10_2012.dat was the determination of $A_{1}$ to $A_{6}$ in the analytical expressions for the equilibrium constants $\left(\log _{-} \mathrm{k}\right)$ in PHREEQC for the reactions with a heat capacity $\left(C_{p}\right.$ in DIN): 
Table 5. Water quality validation data set from DIN consisting of 10 different drinking water samples.

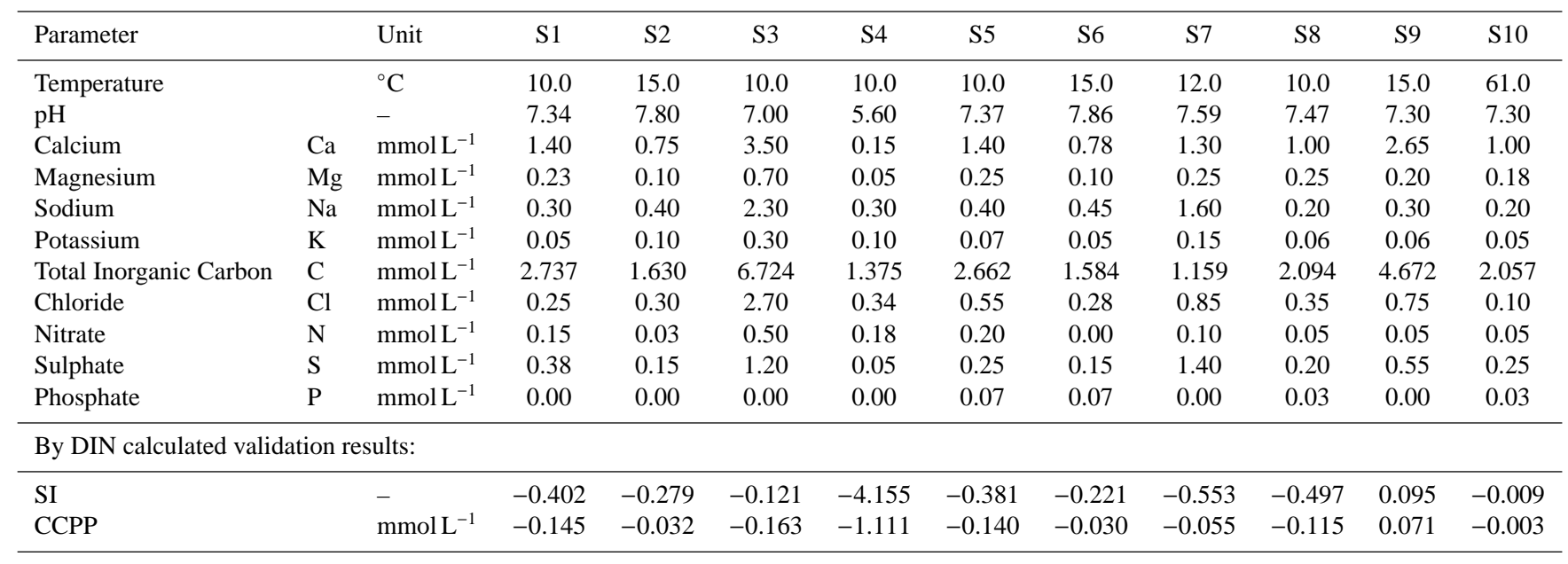

$A_{1}=\lg \left(\mathrm{K}_{0}\right)+\frac{\frac{\Delta \mathrm{H}}{T_{0}}-C_{P}\left(1+\ln \left(T_{0}\right)\right)}{R \ln (10)}$

$A_{2}=A_{5}=A_{6}=0$

$A_{3}=\frac{C_{P} T_{0}-\Delta \mathrm{H}}{R \ln (10)}$

$A_{4}=\frac{C_{P}}{R}$

The temperature related DIN parameters $A$ (constant), $B$ (ion size coefficient), and $D K$ (dielectric constant) in the calculation of the activity coefficients are included in PHREEQC in an equivalent way. DIN assumes no effect of uncharged ions, therefore $b$ in the Debye-Hückel equation as used in WATEQ (Truesdell and Jones, 1974) is set to 0 in din3840410_2012.dat (the default value used in PHREEQC is 0.1).

Similar to the development of the DIN database for PHREEQC, also databases were newly developed for Standard Methods 2330 (sm2330_2010.dat) and NEN 6533 (nen6533_1990.dat) and therefore a number of issues was resolved. In order for PHREEQC to run, $\log \_k$ values for ion pairs need to be defined. However, in SM and NEN ion pairs are not included, see Table 3, therefore the $\log _{-} \mathrm{k}$ values of all reaction equations of these species was set to -100 in "sm2330_2010.dat" and "nen6533_1990.dat". SM uses the Davies equation for the influence of the ionic strength for charged ions according to the default method in PHREEQC, therefore, the gamma option in sm2330_2010.dat has been omitted. NEN uses the WATEQ Debye-Hückel equation for charged ions, thus the gamma option is used in nen6533_1990.dat. For species without charge (including $\mathrm{H}_{2} \mathrm{O}$ and $\mathrm{CO}_{2}$ ) an activity coefficient of 1.0 has been assumed in both sm2330_2010.dat and nen6533_1990.dat ( $b=0$ in gamma). For all calculations with PHREEQC it is assumed that the oxygen content is al- ways $100 \%$ saturated at $1.0 \mathrm{~atm}$ in dry air with an oxygen content of $20.8 \%$.

\subsection{Drinking water validation data set}

For validation of the calculation methods, the data set of 10 water quality validation samples given in DIN was used. The validation data set in DIN contains the measured water quality parameters of the 10 samples. Part of the data is summarized in Table 5, including DIN calculated SI and CCPP values. Actually, in the DIN the Calcitlösekapazität $\left(D_{\mathrm{C}}\right)$ in $\mathrm{mg} \mathrm{L}^{-1}$ is given from which the CCPP in Table $5 \mathrm{in} \mathrm{mmol} \mathrm{L}^{-1}$ is calculated with:

$\mathrm{CCPP}=\frac{-D_{\mathrm{C}}}{\mathrm{MW}_{\mathrm{CaCO}_{3}}}$

The water quality dataset in Table 5 ranges from very soft water (sample 4) to hard water with high sulphate content (sample 3). The water temperature of the samples is between 10 and $15^{\circ} \mathrm{C}$ (sample 1-9), and $61^{\circ} \mathrm{C}$ (sample 10); $\mathrm{pH}$ is between 7.00 and 7.86 (sample 1-3 and 5-10), and 5.60 (sample 4). Sample 4 and sample 10 are outside the scope of DIN ("water for distribution as drinking water") because of $\mathrm{pH}$ respectively temperature. The validation set lacks samples with $\mathrm{pH}$ above 7.86, that is typical for soft and softened drinking water.

According to DIN most water samples in the validation set are slightly calcium carbonate dissolving $\left(-0.2<\mathrm{CCPP}<0.0 \mathrm{mmol} \mathrm{L}^{-1}\right)$, except for sample 4 , which is highly calcium carbonate dissolving, and sample 9 , which has a small calcium carbonate precipitation potential. The parameter alkalinity is not included in Table 5, because for proper comparison of the DIN, SM and NEN standard the sum of inorganic carbon species in a solution is used. The density of the different samples is not given in DIN, as it is based on molarity. Molarity is converted into molality for PHREEQC by assuming a density of $1.0 \mathrm{~kg} \mathrm{~L}^{-1}$ for all 


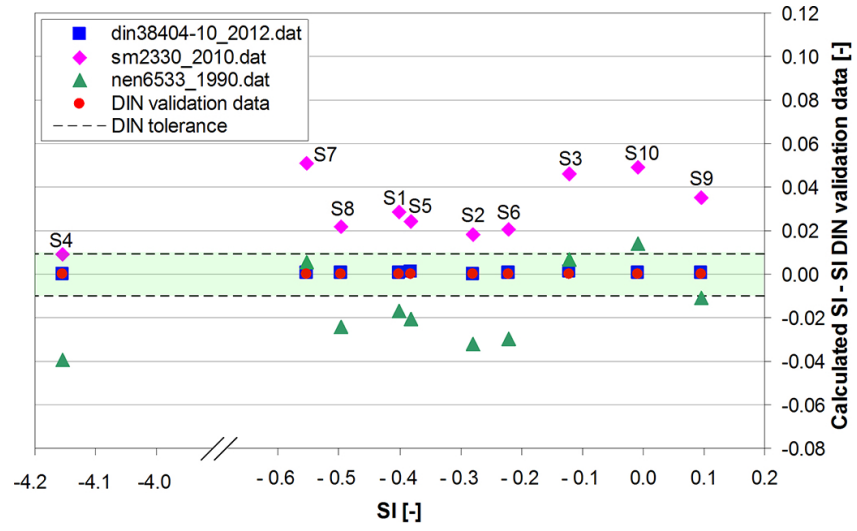

Figure 2. Deviations of the SIs calculated in PHREEQC according to the DIN, SM and NEN standards, from the SIs given in the DIN validation data set for the 10 water quality samples S1 to S10 (see Table 5).

samples, regardless of water temperature. The assumption of a density of $1.0 \mathrm{~kg} \mathrm{~L}^{-1}$ is only used for the calculations with DIN, SM and NEN. For the calculations with the other databases from Table 4, the solution density for conversion from concentrations in $\mathrm{mmol} \mathrm{L}^{-1}$ into $\mathrm{mmol} \mathrm{kgw}^{-1}$ is calculated by PHREEQC itself.

\section{Results}

\subsection{SI for calcium carbonate}

In Fig. 2 the deviations are shown between the SIs calculated in PHREEQC according to the DIN, SM and NEN standards and the SIs according to the DIN validation data set, see Table 5. Also the tolerance for calculated SI values of 0.01 given in the DIN standard is shown in Fig. 2.

From the data shown in Fig. 2, it is observed that the SI values calculated with din38404-10_2012.dat in PHREEQC have a maximal deviation of 0.0011 . The calculation method with din38404-10_2012.dat complies with the DIN standard in which a tolerance of \pm 0.01 SI is specified for the calculation results.

SI values calculated with the SM database are on average 0.030 higher than the SIs according to DIN. This is mainly caused by neglecting ion pairs in SM; more specifically, the ion pair $\mathrm{CaSO}_{4}^{0}$, which leads to an overestimation of the $\mathrm{Ca}^{2+}$ concentration. The overestimation is smaller for sample 4 because of the low concentration of ions in the sample and the overestimation is larger for the samples 3, 7 and 9 with high sulphate concentrations. Almost all calculated SI values are out of the DIN tolerance range.

For most samples, the NEN database provides SI values that are more than 0.01 lower than the DIN database because of the higher $\mathrm{K}_{\mathrm{s}}$ value used in NEN, except for the samples 3, 7 and 10. The NEN database gives better results for the samples 3 and 7 with higher sulphate concentrations than the SM

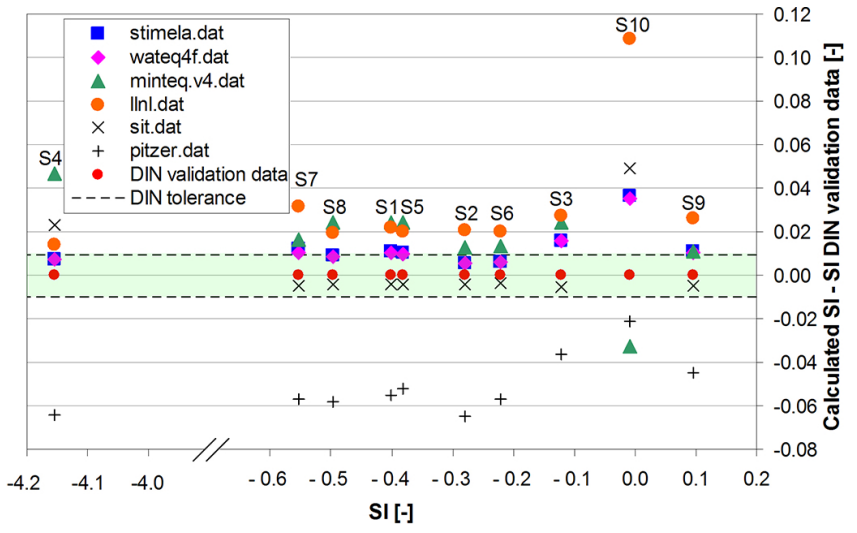

Figure 3. Deviations of the SIs calculated in PHREEQC with widely used chemical databases, from the SIs given in the DIN validation data set for the 10 water quality samples S1 to S10 (see Table 5).

database. This is remarkable since the reason for decreasing $\mathrm{pK}_{\mathrm{s}}$ value in NEN is to take into account the effect of ion pairs $\mathrm{CaCO}_{3}^{0}$ and $\mathrm{CaHCO}_{3}^{+}$, and not $\mathrm{CaSO}_{4}^{0}$ ion pair. Even though the calculation methods of SM and NEN are similar, the lower $\mathrm{pK}_{\mathrm{s}}$ value leads to an almost equal difference of around 0.045 between the two methods. It should be noted that $\mathrm{pK}_{\mathrm{w}}$ in NEN is only validated for a temperature range of 0 to $30^{\circ} \mathrm{C}$; therefore, the calculated SI value for sample 10 with a temperature of $61{ }^{\circ} \mathrm{C}$ is only illustrative.

In Fig. 3 the deviations are shown between the SIs calculated in PHREEQC according to the widely used chemical equilibrium databases and the SIs according to the DIN validation data set, see Table 5. Also the tolerance for calculated SI values of 0.01 given in the DIN standard is shown in Fig. 3.

Differences between the calculated SI values with stimela.dat and the values according to the DIN validation data are on average 0.012 . The differences are caused by small differences in the values of equilibrium constants and activity coefficients, and not by the ion pairs that are present in stimela.dat, but are not present in the DIN standard. For 5 of the 10 samples stimela.dat calculates SI within the tolerance of $0.01 \mathrm{SI}$ as specified in the DIN standard. The larger error observed for sample 10 is caused partly by the fact that DIN neglects the change in density due to the higher temperature.

The SI values calculated with stimela.dat and wateq4f.dat are almost the same for all samples. The SI values with minteq.v4.dat and llnl.dat are, with sample 10 left out, on average 0.022 higher than the SI values according to DIN. This is mainly due to a slight difference in the values of $\lg \mathrm{K}_{2}-\lg \mathrm{K}_{\mathrm{s}}$ for both databases at a temperature between 10 and $15^{\circ} \mathrm{C}$. At $61^{\circ} \mathrm{C}$ (sample 10), the difference in SI for these databases is large due to the large differences in $\mathrm{K}_{\mathrm{s}}$. The large difference in sample 4 for minteq.v4.dat is the overall effect of many small differences that reinforce each other, from which half is caused by a difference in $\lg \left\{\mathrm{HCO}_{3}^{-}\right\}$. 


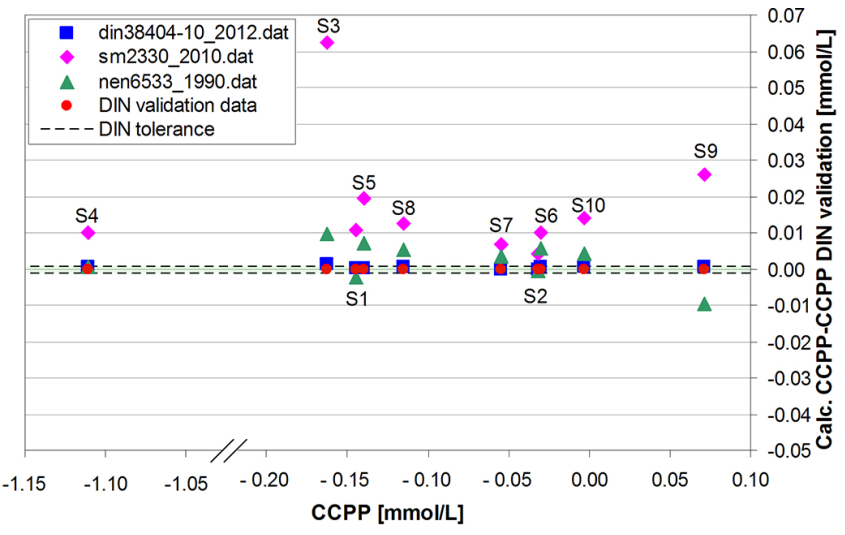

Figure 4. Deviations of the CCPPs calculated in PHREEQC according to the DIN, SM and NEN standards, from the CCPPs given in the DIN validation data set for the 10 water quality samples S1 to S10 (see Table 5).

The database sit.dat gives for most samples a difference of less than 0.01 . The differences are mainly caused by small differences in $\mathrm{K}_{\mathrm{s}}$ and $\mathrm{K}_{2}$. The database pitzer.dat gives large differences up to 0.065 . The differences between stimela.dat and pitzer.dat are entirely due to the difference in the activity of $\mathrm{Ca}^{2+}$ and $\mathrm{HCO}_{3}^{-}$, since $\mathrm{K}_{2}$ and $\mathrm{K}_{\mathrm{s}}$ are the same. It can be observed that the Pitzer model is less suitable for the "low salt" samples given in the DIN standard.

The bandwidth of the calculation results with the comprehensive databases in Fig. 3 is smaller than the bandwidth for the results with the simple calculations according to SM and NEN shown in Fig. 2.

\subsection{Calcium carbonate precipitation potential}

In Fig. 4 the deviations are shown between the CCPPs calculated in PHREEQC according to the DIN, SM and NEN standards and the CCPPs according to the DIN validation data set, see Table 5. Also the tolerance for calculated CCPP values of $0.001 \mathrm{mmol} \mathrm{L}^{-1}$ given in the DIN standard is shown in Fig. 4.

From the data shown in Fig. 4, it is observed that the CCPPs calculated with the DIN database comply with the validation values. The maximum deviation observed is $+0.0011 \mathrm{mmol} \mathrm{L}^{-1}$ (sample 3 ), which is not significantly outof-tolerance.

CCPPs calculated with the SM database give values which are on average $0.018 \mathrm{mmol} \mathrm{L}^{-1}$ higher than CCPPs according to DIN, with a peak of $0.062 \mathrm{mmol} \mathrm{L}^{-1}$ for sample 3 . This is due to neglecting ion pairs in SM. The CCPP calculated with the NEN database always gives lower values than calculated with $\mathrm{SM}$ due to difference in $\mathrm{pK}_{\mathrm{s}}$ as described for SI. The fixed difference in the $\mathrm{pK}_{\mathrm{s}}$ gives variable differences for the CCPP, because of the differences in calcium, carbonate and bicarbonate concentrations in the ten samples. It is noted that $\mathrm{pK}_{\mathrm{w}}$ in NEN is only validated for a temperature range of 0

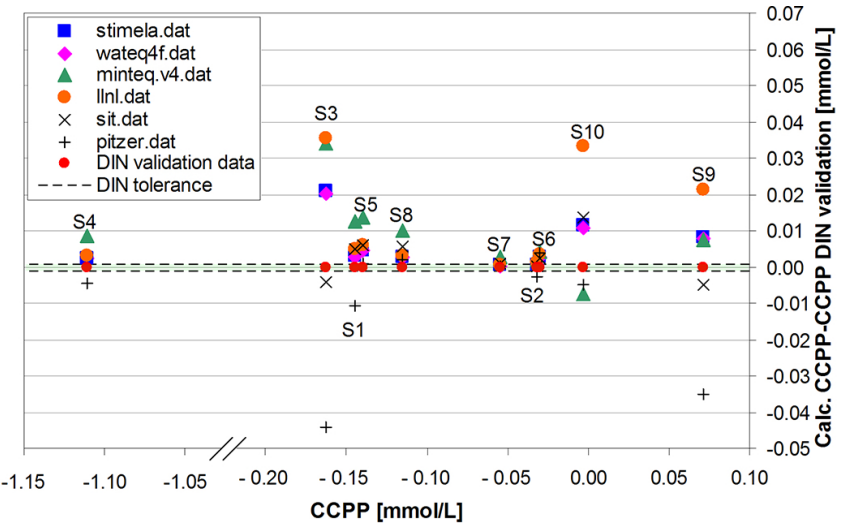

Figure 5. Deviations of the CCPPs calculated in PHREEQC with the widely used chemical databases, from the CCPPs given in the DIN validation data set for the 10 water quality samples $\mathrm{S} 1$ to $\mathrm{S} 10$ (see Table 5).

to $30^{\circ} \mathrm{C}$, therefore the calculated CCPP for sample 10 with a temperature of $61^{\circ} \mathrm{C}$ is only illustrative.

In Fig. 5 the deviations are shown between the CCPPs calculated in PHREEQC according to the widely used chemical equilibrium databases and the CCPPs according to the DIN validation data set, see Table 5. Also the tolerance for calculated CCPPs of $0.001 \mathrm{mmol} \mathrm{L}^{-1}$ given in the DIN standard is shown in Fig. 5.

From the data in Fig. 5 it is observed that for most samples the CCPPs calculated with stimela.dat are 0.000 to $0.005 \mathrm{mmol} \mathrm{L}^{-1}$ ( 0.0 to $0.5 \mathrm{mg} \mathrm{CaCO}_{3} \mathrm{~L}^{-1}$ ) larger than the values in the DIN validation data set. This means that for calcium dissolving water, according to stimela.dat, less $\mathrm{CaCO}_{3}$ might be dissolved than according to the DIN standard. The differences are slightly larger for samples 9 and 10 , and for sample 3 the difference is $0.021 \mathrm{mmol} \mathrm{L}^{-1}$ $\left(2.1 \mathrm{mg} \mathrm{CaCO}_{3} \mathrm{~L}^{-1}\right)$. This difference is caused by accumulation of several small differences, and not by ion pairs which are in stimela.dat but not in din38404-10_2012.dat. For only 2 of the 10 samples stimela.dat calculates CCPP within the tolerance of $0.001 \mathrm{mmol} \mathrm{L}^{-1}$ as specified in the DIN standard.

From the calculation with stimela.dat it is observed that the free ion $\mathrm{Ca}^{2+}$ forms $90-99 \%$ of the total calcium content in all ten samples, the remainder is present as $\mathrm{CaSO}_{4}^{0}, \mathrm{CaHCO}_{3}^{+}$, $\mathrm{CaCO}_{3}^{0}$ and $\mathrm{CaHPO}_{4}^{0}$ (in order of importance). These ion pairs cause the large deviation as mentioned for sample 3 calculated with sm2330_2010.dat. Other ion pairs for Ca are negligible. From the calculation with stimela.dat it can also be observed that the carbon ion pairs are of less importance since all carbon in the 10 samples is $98-100 \%$ present as $\mathrm{CO}_{2}, \mathrm{HCO}_{3}^{-}$or $\mathrm{CO}_{3}^{2-}$. The CCPP values calculated with wateq4f.dat are almost the same as for stimela.dat for all 10 samples.

It can be observed that the differences between the CCPPs from the DIN validation data and the CCPPs calculated 
with minteq.v4.dat, llnl.dat, sit.dat and pitzer.dat are generally larger than the differences calculated with stimela.dat and watq4f.dat, and that all values are generally in the range of $\pm 0.01 \mathrm{mmol} \mathrm{L}^{-1}$. The causes for the differences of minteq.v4.dat, llnl.dat, sit.dat and pitzer.dat are the same as for the differences observed in SI values. The largest differences occur for samples 3 and 9 due to a large influence of the ion pair $\mathrm{CaSO}_{4}^{0}$. In addition, a large difference occurs for sample 10 , which is mainly caused by the differences in $\mathrm{K}_{\mathrm{s}}$ and $\mathrm{K}_{2}$.

\section{Discussion}

\subsection{SI versus CCPP}

SI indicates thermodynamical driving force, while CCPP is total mass $\mathrm{CaCO}_{3}$ reacted to obtain equilibrium. The parameters are not quantitatively related, as shown in Fig. 6, only qualitatively; SI and CCPP are positive for oversaturated water, zero for saturated water, and negative for undersaturated water. In 2003 the German drinking water regulations were changed from SI as the guideline parameter to CCPP ("Calcitlösekapazität"). This approach focuses better on the water quality issue, which is precipitation and dissolution of calcite.

\subsection{Tolerance and accuracy}

For natural water the DIN tolerance range for SI $(0.01)$ and for CCPP $\left(0.001 \mathrm{mmol} \mathrm{L}^{-1}\right)$ are not equivalent. This can be demonstrated by assuming the allowed deviation in $\mathrm{pH}$ for sample 5 (7.38 instead of 7.37) which results in an unaccepted deviation in CCPP of $0.005 \mathrm{mmol} \mathrm{L}^{-1}$ (five times to high).

An error of 0.01 in the log-concentration parameter SI corresponds to errors of $2.3 \%\left(=10^{0.01}\right)$ in concentration of monovalent ions and $1.2 \%\left(=10^{0.01 / 2}\right)$ for bivalent ions, at equal equilibrium constant. Natural soft water with a calcium concentration of $1.0 \mathrm{mmol} \mathrm{L}^{-1}$ would allow for a deviation of $(1.0 \times 1.2 \%=) 0.012 \mathrm{mmol} \mathrm{L}^{-1}$, which is 12 times larger than the tolerance range for CCPP. The tolerances for SI and CCPP are equivalent at a calcium concentration of $(0.001 / 1.2 \%=) 0.083 \mathrm{mmol} \mathrm{L}^{-1}\left(3.3 \mathrm{mg} \mathrm{L}^{-1}\right)$. The DIN dataset has an average calcium concentration of $1.38 \mathrm{mmol} \mathrm{L}^{-1}$ and a lowest concentration of $0.15 \mathrm{mmol} \mathrm{L}^{-1}$. This shows that in DIN the restrictions for CCPP are by far more stringent than for $\mathrm{SI}$ (or $\mathrm{pH}$ ).

The allowable tolerance for SI and CCPP as defined in DIN is smaller than the deviations caused by the inaccuracy of the measurements of the chemical parameters, which form the input of the calculations. The DIN specifies for $\mathrm{pH}$ a tolerance of 0.05 based on determination of $p$ value (acidity), $m$ value (alkalinity), measured $\mathrm{pH}$ and calculated $\mathrm{pH}$. Consequently, 0.05 is also the minimal accuracy for SI, which is 5 times larger than the tolerance of the SI calculation of

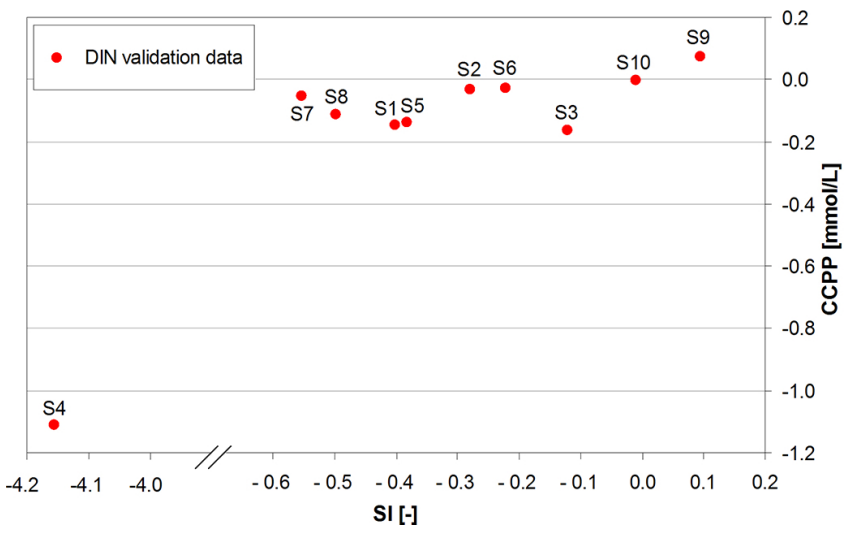

Figure 6. CCPP values plotted against the SI (data from the DIN validation data set, see Table 5).

0.01 defined in DIN. The DIN specifies a minimal accuracy for the ionic balance of $5 \%$ (ionic strength $>4 \mathrm{mmol} \mathrm{L}^{-1}$ ) to $10 \%$ (ionic strength $<4 \mathrm{mmol} \mathrm{L}^{-1}$ ) which can be adopted as minimal accurary levels for calcium and alkalinity. Depending on the ionic strength, natural soft water with a calcium concentration of $1.0 \mathrm{mmol} \mathrm{L}^{-1}$ would allow for a deviation of $(1.0 \times 5 \%=) 0.05 \mathrm{mmol} \mathrm{L}^{-1}$ to $(1.0 \times 10 \%=) 0.1 \mathrm{mmol} \mathrm{L}^{-1}$, which is 50 to 100 times larger than the DIN tolerance range for calculation of CCPP. Figures 2 to 5 show that almost all presented models for the calculation of SI and CCPP comply with a tolerance range of 0.05 for SI and 0.05 to $0.1 \mathrm{mmol} \mathrm{L}^{-1}$ for CCPP. It would be preferable to introduce tolerances for SI and CCPP which are consistent with each other and based on practical accuracy of the measurements of at least $\mathrm{pH}$ (including the DIN accuracy check) and calcium.

\subsection{Molarity versus molality}

The equations for equilibrium in DIN are based on the obsolete molarity system $\left(\mathrm{mol} \mathrm{L}^{-1}\right)$. Modern chemistry uses molality $\left(\mathrm{mol} \mathrm{kgw}^{-1}\right)$. For drinking water with its low salt content and its temperature between 0 and $25^{\circ} \mathrm{C}$ the difference is very small. However at higher temperatures, the difference in density is no longer negligible. Above $45^{\circ} \mathrm{C}$ the density is below $0.99 \mathrm{~kg} \mathrm{~L}^{-1}$ giving differences in concentration above $1 \%$. The density of sample 10 in the DIN validation set is $0.983 \mathrm{~kg} \mathrm{~L}^{-1}$, as calculated by PHREEQC with stimela.dat. The differences in SI and CCPP calculated according to DIN due to neglecting changes in density are respectively 0.013 and $0.004 \mathrm{mmol} \mathrm{L}^{-1}$. This makes the applicability of DIN for water with a temperature higher than $45^{\circ} \mathrm{C}$ unjustified and sample 10 should therefore be omitted from the DIN validation database.

\subsection{Warm, hot and boiling water}

DIN and NEN are only applicable in lower temperature water. NEN gives as temperature range 0 to $30^{\circ} \mathrm{C}$, while DIN 
does not give temperature limits but from the calculations performed in this research it is found that it is valid up to a range of 40 to $50^{\circ} \mathrm{C}$. Standard Methods gives a temperature range for $\mathrm{K}_{\mathrm{s}}$ and $\mathrm{K}_{2}$ of 0 to $90^{\circ} \mathrm{C}$, according to Plummer and Busenberg (1982). For drinking water practice the temperature range should be extended up to $100^{\circ} \mathrm{C}$ since customers heat up and boil water and scaling of calcium carbonate is a critical factor for in-house drinking water practices. This requires that equilibrium constants and activity coefficients used for calculation of SI and CCPP should be valid in the temperature range of 0 to $100^{\circ} \mathrm{C}$.

In addition, the vapor pressure of water is important, in combination with the concentrations of dissolved gases. At a higher vapor pressure the gas partial pressure of $\mathrm{N}_{2}, \mathrm{O}_{2}$, $\mathrm{CO}_{2}$ might result in degassing and therefore in a reduction of $\mathrm{CO}_{2}$ content. This process occurs during gas bubble formation when heating water, which already occurs below the boiling point of water. The partial pressure of oxygen in contact with wet air is around $0.20 \mathrm{~atm}$ for water samples 1 to 9 from the DIN validation set with water temperatures from 10 to $15^{\circ} \mathrm{C}$, and $0.16 \mathrm{~atm}$ for sample 10 with a temperature of $61{ }^{\circ} \mathrm{C}$.

The current standards do not fulfil the need from drinking water practice to include calculation of calcium carbonate scaling at high temperatures. In future research, the effect of higher temperatures up to $100^{\circ} \mathrm{C}$ on calcium carbonate saturation in drinking water will be assessed. In this research stimela.dat, which is based on phreeqc.dat, will be used since values for equilibrium constants and activity coefficients are valid up to $100^{\circ} \mathrm{C}$ and effects of degassing can be taken into account.

\subsection{Scientific justification}

The chemical databases and standards appear to have significant differences in the values of the equilibrium constants. The influence of the difference in activity coefficients is less significant, with the exception of the unsuitable models (SIT and Pitzer) which have not been calibrated for potable water with a low ionic strength. An international standardization of this basic chemistry is performed within the "IUPAC-NIST Solubility Data Series" of the International Union for Pure and Applied Chemistry (IUPAC) and the National Institute of Standards and Technology (NIST). A volume on alkaline earth carbonates has been published recently (de Visscher et al., 2012; de Visscher and Vanderdeelen, 2012). The values of $\mathrm{K}_{\mathrm{s}}, \mathrm{K}_{1}, \mathrm{~K}_{2}$ and $\mathrm{K}_{\mathrm{w}}$ in phreeqc.dat and thus in stimela.dat appear to be well in accordance with the presented results.

It is expected that the results will be considered by USGS for future versions of phreeqc.dat and will consequently be adopted in stimela.dat. Pending this scientific justification, the $K$ values in stimela.dat will be used in further research, according to Nordstrom et al. (1990), mainly because of the wide temperature range. This approach is in compliance with Standard Methods 2330 D.

\section{Conclusions}

The computer program PHREEQC (USGS, 2013) with the developed chemical database din38404-10_2012.dat complies with the new German standard DIN 38404-10 (2012) for calculating SI and CCPP. This standard covers water that is intended for distribution as drinking water with its specific limitations on concentrations and temperature. This compliance is achieved by assuming equal values for molarity as used in DIN (obsolete) and molality as used in PHREEQC. From comparison with widely used chemical databases it is concluded that the use of molarity limits the use of DIN to a maximum temperature of $45^{\circ} \mathrm{C}$. Alternative international standards (Standard Methods and NEN) are not accurate enough to comply with DIN, because of their simplifications. It should be noted that the DIN tolerance range is more stringent than the accuracy of the chemical analyses which serve as input for the computer calculations. On the other hand, the differences in calculation results for DIN, SM and NEN illustrate the need for international unification of these standards. Running extensive chemical models i.e. databases on the DIN validation data set results in deviations outside the DIN tolerance range. None of these widely used models fully complies with the DIN standard. However, it must be noted that all models, including DIN, lack proper scientific justification and/or scientific acceptance. This might be achieved in the near future within the framework of the "IUPAC-NIST Solubility Data Series" of the International Union for Pure and Applied Chemistry (IUPAC) and the National Institute of Standards and Technology (NIST). For application of drinking water supply it is concluded that the standards should also be applicable for hot and boiling water, since scaling of calcium carbonate is a critical factor for in-house drinking water practices. For current practical applications the PHREEQC database stimela.dat was developed within the Stimela platform of Delft University of Technology. This database is an extension of phreeqc.dat focused on water treatment and drinking water applications. This approach is in compliance with Standard Methods 2330 D.

\section{Supplementary material}

For use of the Supplement the free software phreeqc3.0.6-7757.msi and IPhreeqcCOM-3.0.6-7757-win32.msi or a higher version should be installed. List of files:

- CalciumCarbonateSaturation_v20131020.xlsm containing din38404-10_2012.dat and the DIN validation data set

- din38404-10_2012.dat

- sm2330_2010.dat

- nen6533_1990.dat

- stimela.dat 
- DIN38404-10_compliance.pqi

\section{Supplementary material related to this article is available online at http://www.drink-water-eng-sci.net/ 6/115/2013/dwes-6-115-2013-supplement.zip.}

Edited by: P. Le-Clech

\section{References}

Buck, R. P., Rondinini, S., Covington, A. K., Bauke, F. G. K., Bretts, C. M. A., Camõus, M. F., Milton, M. J. T., Mussini, T., Naumann, R., Pratt, K. W., Spitzer, P., and Wilson, G. S.: Measurement of $\mathrm{pH}$. Definition, standards and procedures (IUPAC Recommendations 2002), Pure Appl. Chem., 74, 2169-2200, 2002.

Daveler, S. A. and Wolery, T. J.: EQPT, A data file preprocessor for the EQ3/6 software package: User's guide and related documentation (Version 7.0), Lawrence Livermore National Laboratory, Livermore, USA, UCRL-MA-110662 PT II, 1992.

de Moel, P. J., van Dijk, J. C., and van der Meer, W. G. J.: Aquatic chemistry for engineers - Volume 1 - Starting with PHREEQC 3, Delft University of Technology, Delft, the Netherlands, 2013.

de Visscher, A. and Vanderdeelen, J.: IUPAC-NIST Solubility Data Series. 95. Alkaline earth carbonates in aqueous systems. Part 2. Ca, J. Phys. Chem. Ref. Data, 41, 023105-1-023105-137, 2012. de Visscher, A., Vanderdeelen, J., Königsberger, E., Churagulov, B. R., Ichikuni, M., and Tsurumi, M.: IUPAC-NIST Solubility Data Series. 95. Alkaline earth carbonates in aqueous systems. Part 1. Introduction, Be and Mg, J. Phys. Chem. Ref. Data, 41, 0131051-013105-67, 2012.

DIN 38404-10: German standard methods for the examination of water, waste water and sludge - Physical and physico-chemical parameters (group C) - Part 10: Calculation of the calcit saturation of water (C 10), DIN Deutsches Institut für Normung, Berlin, Germany, 2012.

Gamsjäger, H., Lorimer, J. W., Scharlin, P., and Shaw, D. G.: Glossary of terms related to solubility (IUPAC Recommendations 2008), J. Pure Appl. Chem., 80, 233-276, 2008.

Grenthe, I., Plyasunov, A. V., and Spahiu, K.: Estimations of medium effects on thermodynamic data, Modelling in aquatic chemistry, edited by: Grenthe, I. and Puigdomenech, I., OECD Nuclear Energy Agency, Paris, France, 1997.
Jacobson, R. L. and Langmuir, D.: Dissociation constants of calcite and $\mathrm{CaHCO}_{3}^{+}$from 0 to $50^{\circ} \mathrm{C}$, Geochim. Cosmochim. Ac., 38, 301-318, 1974.

Langelier, W. F.: The analytical control of anti-corrosion water treatment, J. Am. Water Works Assoc., 28, 1500-1521, 1936.

NEN 6533: Water - Bepaling van de agressiviteit ten opzichte van calciumcarbonaat en berekening van de verzadigingsindex (Water - Determination of the agressivity to calcium carbonate and the calculation of the saturation index), Nederlands Normalisatie-insituut, Delft, the Netherlands, 1990.

Nordstrom, D. K., Plummer, L. N., Langmuir, D., Busenberg, E., May, H. M., Jones, B. F., and Parkhurst, D. L.: Revised chemical equilibrium data for major water-mineral reactions and their limitations, in: Chemical modeling in aqueous systems II (Symposium Series 416), edited by: Bassett, D. and Melchior, R. L., American Chemical Society, Washington D.C., USA, 1990.

Parkhurst, D. L. and Appelo, C. A. J.: Description of input and examples for PHREEQC version 3 - A computer program for speciation, batch-reaction, one-dimensional transport, and inverse geochemical calculations, US Geological Survey, Denver, USA, 2013.

Pitzer, K. S.: Thermodynamics of electrolytes. I. Theoretical basis and general equations, J. Phys. Chem., 77, 268-277, 1973.

Plummer, L. N. and Busenberg, E.: The solubilities of calcite, aragonite and vaterite in $\mathrm{CO}_{2}-\mathrm{H}_{2} \mathrm{O}$ solutions between 0 and $90^{\circ} \mathrm{C}$, and an evaluation of the aqueous model for the system $\mathrm{CaCO}_{3}$ $\mathrm{CO}_{2}-\mathrm{H}_{2} \mathrm{O}$, Geochim. Cosmochim. Ac., 46, 1011-1040, 1982.

Standard Methods 2330: Calcium carbonate saturation (2330), American Public Health Association/American Water Works Association/Water Environment Federation, Baltimore, USA, 2010.

Stumm, W. and Morgan, J. J.: Aquatic chemistry - Chemical equilibria and rates in natural waters (3rd Edn.), John Wiley \& sons, New York, USA, 1996.

Truesdell, A. H. and Jones, B. F.: WATEQ, A computer program for calculating chemical equilibria of natural waters, J. Res. US Geol. Survey, 2, 233-248, 1974.

USGS: phreeqc-3.0.6-7757.msi, http://wwwbrr.cr.usgs.gov/ projects/GWC_coupled/phreeqc/, last access: 23 October 2013.

van der Helm, A. W. C. and Rietveld, L. C.: Modelling of drinking water treatment processes within the Stimela environment, Wa. Sci. Technol., 2, 87-93, 2002. 